\title{
Population Structure and Genetic Diversity of Phytophthora nicotianae from Tobacco in Georgia
}

Yonggang Li, Agricultural College, Northeast Agricultural University, Harbin 150030, China; and Department of Plant Pathology, University of Georgia, Tifton 31794; Karen Harris-Shultz and Hongliang Wang, United States Department of Agriculture-Agricultural Research Service (USDA-ARS), Crop Genetics and Breeding Research Unit, Tifton, GA 31793; Phillip A. Wadl, USDA-ARS, U.S. Vegetable Laboratory, Charleston, SC 29414; and Pingsheng Ji, Department of Plant Pathology, University of Georgia, Tifton

\begin{abstract}
Black shank, caused by Phytophthora nicotianae, occurs worldwide and is responsible for significant yield loss in tobacco production in Georgia. Management of the disease has primarily relied on utilization of tobacco cultivars with resistance to race 0 of the pathogen and application of the fungicide mefenoxam. Races of $P$. nicotianae currently prevalent in tobacco production in Georgia, their sensitivity to mefenoxam, and genetic diversity of the pathogen are largely unknown. To determine population structure and genetic diversity of the pathogen, simple sequence repeat (SSR) markers were used. Three races of $P$. nicotianae (races 0,1 , and 3 ) were isolated from infected tobacco plants, with race 3 identified in Georgia for the first time. The majority of isolates were identified as A2 mating type and all isolates were sensitive or intermediately sensitive to mefenoxam at 1 or $10 \mu \mathrm{g} / \mathrm{ml}$, with effective concentration of mefenoxam for $50 \%$ mycelial growth reduction values ranging from $<0.01$ to $0.12 \mu \mathrm{g} / \mathrm{ml}$. Bayesian and unweighted pair group method with

arithmetic means analyses of 59 isolates using SSR markers grouped the isolates in two major groups. Group I contained 20 isolates, of which 19 isolates were collected from Berrien County. Group II contained 39 isolates collected from Bacon, Cook, Tift, and Toombs Counties as well as one sample from Berrien County. Genetic diversity of the isolates was associated with geographical location of collection, and isolates in group I were primarily (75\%) race 1 , whereas isolates in group II were primarily (69\%) race 0 . The presence of a single pathogen mating type at most of the locations implies low probability of sexual recombination that may have contributed to the low genetic diversity at a particular geographical location. Sensitivity of the isolates to mefenoxam indicates that the fungicide remains to be a potent tool for growers to combat the disease. Information generated in the study advances our knowledge about diversity and population structure of $P$. nicotianae, which facilitates development and implementation of effective disease management programs.
\end{abstract}

Phytophthora nicotianae Breda de Haan, the causal agent of tobacco black shank, occurs worldwide and infects a variety of plant species. It is a soilborne pathogen and also named $P$. parasitica var. nicotianae (Breda de Haan) Tucker and P. nicotianae var. nicotianae G. M. Waterhouse (Erwin and Ribeiro 1996). The pathogen is destructive on tobacco (Nicotiana tabacum), causing significant quality and yield loss in the southeastern United States. Common symptoms caused by black shank include root rot and necrosis of lower stems, leaf yellowing, plant stunting, and wilting (Csinos and Bertrand 1994; Shew and Lucas 1998).

$P$. nicotianae is a diversified pathogen, with four races currently identified. Race 0 isolates are not pathogenic on tobacco carrying $P h p$ or $P h l$ genes, whereas race 1 isolates cause disease on tobacco with these genes (Apple 1967). Some isolates in South Africa were designated as race 2 and had differential responses to ' $\mathrm{KY} 14 \mathrm{xL8}$ ' and 'Burley 21xL8' tobacco, and did not cause disease on 'Delcrest 202' (Lamprecht et al. 1974). Race 3 isolates caused disease on tobacco with the $P h l$ gene but were not pathogenic on tobacco carrying the Php gene (McIntyre and Taylor 1978). Races 0 and 1 are widely distributed worldwide, race 2 was identified in South Africa only, and race 3 was reported in the eastern United States, including Connecticut, North Carolina, and Virginia (Gallup and Shew 2010; McIntyre and Taylor 1978; Parkunan et al. 2010).

Management of black shank of tobacco is a challenging task due to the diversity of the pathogen, especially the aggressiveness of race 1 strains on tobacco cultivars. Due to the wide distribution of race 1, reliance on cultivars with resistance to race 0 strains is not sufficient to manage the disease effectively. Application of fungicides is commonly used by growers to reduce the disease, although only limited fungicides are available for effective black shank management. The

Corresponding author: P. Ji; E-mail: pji@uga.edu

Accepted for publication 16 March 2017.

@ 2017 The American Phytopathological Society most widely used fungicide to control tobacco black shank is mefenoxam, and it was only recently that some newer fungicides were demonstrated to be effective alternative or complementary tools to combat the disease (Ji et al. 2014; Qu et al. 2016). P. nicotianae isolated in Georgia from tobacco was found to be sensitive to mefenoxam two decades ago (Csinos and Bertrand 1994). It was reported that reduced sensitivity to mefenoxam might occur in $P$. nicotianae populations following continuous application of the compound (Shew 1985). Hence, it is desirable to evaluate potential resistance of $P$. nicotianae populations currently prevalent in tobacco production to mefenoxam to determine this fungicide's usefulness for managing black shank.

Although it has long been known that $P$. nicotianae from tobacco is diversified, with different races, limited information is available regarding genetic diversity of the pathogen and the potential relationship between pathogen genetic diversity and other traits such as races. In a recent study (Biasi et al. 2016), genetic diversity of $P$. nicotianae strains from different host plants was assessed by simple sequence repeat (SSR) analysis, which indicated that genetic grouping was strongly associated with host types from which the strains were isolated. SSR are tandemly repeated motifs in the nuclear genomes of eukaryotic organisms. They are highly polymorphic, multiallelic, evenly dispersed throughout the genome, and have been an efficient marker system in studies of the genetic variation of Phytophthora spp. (Biasi et al. 2016; Wang et al. 2009). Hence, the objectives of this research were to develop SSR markers for $P$. nicotianae and study genetic and phenotypic variations of $P$. nicotianae causing black shank of tobacco in Georgia. Information generated in the study enhances our understanding of population structure of the pathogen and facilitates development of effective programs to manage the disease.

\section{Materials and Methods}

Isolates of $\boldsymbol{P}$. nicotianae and race determination. Isolates of $P$. nicotianae were collected in Georgia from infected tobacco plants in 2013 and 2014, and generation of single-spore isolates and their pathogenicity on tobacco ('K326') was reported previously (Qu et al. 2016). Fifty-nine single-spore isolates from different counties in Georgia were used for race determination in this study (Table 1). 
Table 1. Location of isolation, races, and sensitivity to mefenoxam of 59 Phytophthora nicotianae isolates from tobacco in Georgia

\begin{tabular}{|c|c|c|c|c|c|c|c|}
\hline \multirow[b]{2}{*}{ Isolate } & \multirow[b]{2}{*}{ County } & \multicolumn{3}{|c|}{$\begin{array}{l}\text { Disease incidence on } \\
\text { tobacco cultivar }(\%)\end{array}$} & \multirow[b]{2}{*}{ Race } & \multicolumn{2}{|c|}{$\begin{array}{l}\text { Sensitivity to } \\
\text { mefenoxam }^{\text {a }}\end{array}$} \\
\hline & & L8 & NC1071 & K326 & & $1 \mu \mathrm{g} / \mathrm{ml}$ & $10 \mu \mathrm{g} / \mathrm{ml}$ \\
\hline Y302 & Toombs & 0 & 0 & 100 & 0 & $\mathrm{~S}$ & $\mathrm{~S}$ \\
\hline Y504 & Toombs & 0 & 0 & 100 & 0 & $\mathrm{~S}$ & S \\
\hline Y203 & Bacon & 0 & 0 & 100 & 0 & I & $\mathrm{S}$ \\
\hline Y503 & Toombs & 0 & 0 & 100 & 0 & $\mathrm{~S}$ & $\mathrm{~S}$ \\
\hline Y201 & Bacon & 100 & 0 & 100 & 3 & I & I \\
\hline Y305 & Toombs & 0 & 0 & 100 & 0 & $S$ & $\mathrm{~S}$ \\
\hline Pn202A & Cook & 100 & 100 & 100 & 1 & $\mathrm{~S}$ & $\mathrm{~S}$ \\
\hline Pn29A & Tift & 100 & 100 & 100 & 1 & I & I \\
\hline Y301 & Toombs & 0 & 0 & 100 & 0 & S & $\mathrm{S}$ \\
\hline $\mathrm{Pn} 40 \mathrm{~A}$ & Tift & 100 & 100 & 100 & 1 & I & $\mathrm{S}$ \\
\hline Pn13B & Berrien & 100 & 100 & 100 & 1 & I & I \\
\hline Pn38A & Tift & 0 & 0 & 100 & 0 & $\mathrm{~S}$ & $\mathrm{~S}$ \\
\hline Y104 & Bacon & 0 & 0 & 100 & 0 & $\mathrm{~S}$ & $\mathrm{~S}$ \\
\hline Pn32A & Tift & 0 & 0 & 100 & 0 & $\mathrm{~S}$ & $\mathrm{~S}$ \\
\hline Pn27A & Tift & 0 & 0 & 100 & 0 & $\mathrm{~S}$ & $\mathrm{~S}$ \\
\hline Pn21A & Tift & 100 & 100 & 100 & 1 & I & $\mathrm{S}$ \\
\hline Pn206A & Cook & 100 & 0 & 100 & 3 & $\mathrm{~S}$ & $\mathrm{~S}$ \\
\hline $\operatorname{Pn} 25 A$ & Tift & 0 & 0 & 100 & 0 & $\mathrm{~S}$ & $\mathrm{~S}$ \\
\hline Pn26A & Tift & 0 & 0 & 100 & 0 & $\mathrm{~S}$ & $\mathrm{~S}$ \\
\hline Pn36A & Tift & 100 & 100 & 100 & 1 & I & $\mathrm{S}$ \\
\hline Pn30A & Tift & 100 & 0 & 100 & 3 & I & $\mathrm{S}$ \\
\hline Y304 & Toombs & 0 & 0 & 100 & 0 & $\mathrm{~S}$ & $\mathrm{~S}$ \\
\hline Y205 & Bacon & 0 & 0 & 100 & 0 & $\mathrm{~S}$ & $\mathrm{~S}$ \\
\hline Y103 & Bacon & 0 & 0 & 100 & 0 & S & $\mathrm{S}$ \\
\hline Pn28A & Tift & 0 & 0 & 100 & 0 & $\mathrm{~S}$ & $\mathrm{~S}$ \\
\hline Pn201A & Cook & 0 & 0 & 100 & 0 & I & $\mathrm{S}$ \\
\hline Y406 & Toombs & 0 & 0 & 100 & 0 & $\mathrm{~S}$ & $\mathrm{~S}$ \\
\hline Y306 & Toombs & 0 & 0 & 100 & 0 & $\mathrm{~S}$ & $\mathrm{~S}$ \\
\hline Pn204A & Cook & 100 & 0 & 100 & 3 & $\mathrm{~S}$ & $\mathrm{~S}$ \\
\hline Y303 & Toombs & 0 & 0 & 100 & 0 & $\mathrm{~S}$ & $\mathrm{~S}$ \\
\hline Pn207A & Cook & 0 & 0 & 100 & 0 & I & $\mathrm{S}$ \\
\hline Y102 & Bacon & 100 & 100 & 100 & 1 & S & $\mathrm{S}$ \\
\hline Pn34A & Tift & 100 & 100 & 100 & 1 & S & $\mathrm{S}$ \\
\hline Pn205A & Cook & 0 & 0 & 100 & 0 & $\mathrm{~S}$ & $\mathrm{~S}$ \\
\hline Pn37A & Tift & 0 & 0 & 100 & 0 & $\mathrm{~S}$ & $\mathrm{~S}$ \\
\hline Pn23A & Tift & 0 & 0 & 100 & 0 & $\mathrm{~S}$ & $\mathrm{~S}$ \\
\hline Pn33A & Tift & 0 & 0 & 100 & 0 & I & $\mathrm{S}$ \\
\hline Pn39A & Tift & 0 & 0 & 100 & 0 & I & $\mathrm{S}$ \\
\hline Pn203A & Cook & 0 & 0 & 100 & 0 & I & $\mathrm{S}$ \\
\hline Pn105A & Berrien & 0 & 0 & 100 & 0 & I & $S$ \\
\hline $\mathrm{Pn} 12 \mathrm{~A}$ & Berrien & 0 & 0 & 100 & 0 & I & $\mathrm{S}$ \\
\hline Pn6A & Berrien & 100 & 100 & 100 & 1 & $\mathrm{~S}$ & $\mathrm{~S}$ \\
\hline Pn18B & Berrien & 0 & 0 & 100 & 0 & $S$ & $\mathrm{~S}$ \\
\hline Pn110A & Berrien & 100 & 100 & 100 & 1 & $\mathrm{~S}$ & $\mathrm{~S}$ \\
\hline Pn108A & Berrien & 100 & 100 & 100 & 1 & S & $\mathrm{S}$ \\
\hline Pn19A & Berrien & 100 & 100 & 100 & 1 & I & $\mathrm{S}$ \\
\hline Pn112A & Cook & 100 & 100 & 100 & 1 & I & $\mathrm{S}$ \\
\hline Pn102A & Berrien & 100 & 100 & 100 & 1 & I & $\mathrm{S}$ \\
\hline Pn13A & Berrien & 100 & 100 & 100 & 1 & I & $\mathrm{S}$ \\
\hline Pn104A & Berrien & 100 & 0 & 100 & 3 & I & $\mathrm{S}$ \\
\hline Pn15A & Berrien & 100 & 100 & 100 & 1 & I & $\mathrm{S}$ \\
\hline Pn109A & Berrien & 100 & 100 & 100 & 1 & I & $\mathrm{S}$ \\
\hline Pn18A & Berrien & 100 & 0 & 100 & 3 & I & S \\
\hline $\mathrm{Pn} 2 \mathrm{~A}$ & Berrien & 100 & 100 & 100 & 1 & I & $\mathrm{S}$ \\
\hline Pn15B & Berrien & 100 & 100 & 100 & 1 & $\mathrm{~S}$ & $\mathrm{~S}$ \\
\hline Pn19B & Berrien & 100 & 100 & 100 & 1 & I & $\mathrm{S}$ \\
\hline Pn103A & Berrien & 100 & 100 & 100 & 1 & I & $\mathrm{S}$ \\
\hline Pn14A & Berrien & 100 & 100 & 100 & 1 & I & $\mathrm{S}$ \\
\hline Pn20A & Berrien & 100 & 100 & 100 & 1 & $\mathrm{~S}$ & $\mathrm{~S}$ \\
\hline
\end{tabular}

a Sensitivity to mefenoxam was determined based on in vitro mycelial growth. $\mathrm{S}=$ sensitive (i.e., mycelial growth on mefenoxam-amended agar plates was less than $30 \%$ of that on the control plates) and $\mathrm{I}=$ intermediate sensitive (i.e., mycelial growth on mefenoxam-amended agar plates was 30 to $90 \%$ of the control).
Three genotypes of tobacco that have different degrees of resistance to $P$. nicotianae were used, including K326 that has no resistance genes and breeding lines 'NC1071' and 'L8' that have the Php gene and $P h l$ gene, respectively (Gallup and Shew 2010). L8 is susceptible to race 3, and both NC1071 and L8 are susceptible to race 1 but resistant to race $0 . \mathrm{K} 326$ is susceptible to all races $(0,1$, and 3$)$.

To prepare inoculum, 50 autoclaved wheat seeds $\left(30 \mathrm{~min}\right.$ at $121^{\circ} \mathrm{C}$ for 3 consecutive days) were placed on a V8 agar plate with a mycelial plug $(0.7 \mathrm{~cm}$ in diameter) of $P$. nicotianae isolates at the center of the plate. After incubating for 10 days at $25^{\circ} \mathrm{C}$, wheat seed fully colonized by mycelium were utilized to inoculate seedlings of tobacco, as described previously (Qu et al. 2016). Briefly, tobacco seed (K326, $\mathrm{L} 8$, and NC1071) were sown in potting mix/sand $(2: 1, \mathrm{vol} / \mathrm{vol})$ in $15-\mathrm{cm}$ pots and 3 -week-old seedlings were transplanted into seedling trays (cells of 3.6 by 3.6 by $6.0 \mathrm{~cm}$ ) in the potting mix/sand. One seedling was transplanted into a cell, and each seedling was inoculated by placing two wheat seeds near the plant under the soil surface 10 days after transplanting. Experimental design was a randomized complete block and three replicates were used, with one plant for an isolate or tobacco genotype for each replicate. Three plants inoculated with autoclaved wheat seed were used as a control for each tobacco genotype. The seedlings were incubated at 20 and $30^{\circ} \mathrm{C}$ (night and day, respectively) in a greenhouse with a 12-h photoperiod, and watered daily using a sprinkler. Percent diseased plants (disease incidence) was recorded once a week for 2 weeks following inoculation. The experiment was repeated one more time under similar conditions. Diseased plants were sampled for isolation and confirmation of the causal agent, as described in our previous study $(\mathrm{Qu}$ et al. 2016).

Determining mating types of $\boldsymbol{P}$. nicotianae isolates. Mycelial plugs ( $7 \mathrm{~mm}$ in diameter) from 7-day-old isolates grown on V8 agar at $25^{\circ} \mathrm{C}$ were transferred to $\mathrm{V} 8$ plates $(9 \mathrm{~cm}$ in diameter) and paired with $P$. nicotianae isolates of known A1 and A2 mating types. Each of the 59 P. nicotianae isolates was placed $3 \mathrm{~cm}$ apart from an A1 or A2 isolate on a plate. The test isolates were also paired with themselves. Three plates were used for each pairing and the plates were wrapped with Parafilm and incubated at $25^{\circ} \mathrm{C}$. Production of oospores was observed periodically under a microscope until 6 weeks after incubation and the experiment was conducted twice.

Determining sensitivity of $\boldsymbol{P}$. nicotianae isolates to mefenoxam. Ridomil Gold (45.3\% mefenoxam) provided by Syngenta (Greensboro, NC) was used to make a stock solution in sterile distilled water. The stock solution was used to amend V8 agar at mefenoxam concentrations of 0 (used as a control), 0.01, 0.1, 0.25, 0.5, 1, and $10 \mu \mathrm{g} / \mathrm{ml}$. After being grown on V8 agar for 7 days $\left(25^{\circ} \mathrm{C}\right)$, a mycelial plug of $P$. nicotianae isolate was transferred to a mefenoxamamended plate. The 59 isolates were tested with three plates for each isolate-fungicide concentration combination. After incubating for 7 days at $25^{\circ} \mathrm{C}$, colony diameters were measured and effective concentration of mefenoxam for $50 \%$ mycelial growth reduction $\left(\mathrm{EC}_{50}\right)$ was calculated using the previously described methods $(\mathrm{Qu}$ et al. 2016). The percentage of resistant (colony size $>90 \%$ of the control), intermediately sensitive (30 to $90 \%$ of the control), and sensitive ( $<30 \%$ of the control) isolates was calculated. Data from two repeated tests were pooled for calculation of $\mathrm{EC}_{50}$ and percentage of resistant or sensitive isolates.

Designing SSR. The $P$. nicotianae isolate INRA-310 (syn. P. parasitica, National Center for Biotechnology Information accession number PRJNA259235) genome sequence was used for SSR discovery. Scaffolds of less than $100 \mathrm{~kb}$ were screened for SSR motifs and primer pairs were designed using BatchPrimer3 (You et al. 2008). Due to size limitations in uploading files to BatchPrimer3, longer scaffolds were not screened. From the 109 primer pairs, 20 were selected with the longest SSR repeat length (24 to $66 \mathrm{bp}$ ).

Determining genetic diversity of $\boldsymbol{P}$. nicotianae isolates. Twenty SSR primer pairs were screened for polymorphisms using 10 P. nicotianae isolates. After incubating on $\mathrm{V} 8$ agar at $25^{\circ} \mathrm{C}$ for 7 days, mycelium of the isolates was scraped using a sterilized scalpel, and approximately $0.1 \mathrm{~g}$ of mycelium was put in each $1.5-\mathrm{ml}$ microcentrifuge tube. The mycelium was ground in liquid nitrogen using a 
pestle, and DNA was extracted using the DNeasy Plant Mini Kit (Qiagen, Valencia, CA). DNA concentration was quantified by a NanoDrop spectrophotometer (Thermo Fisher Scientific, Waltham, MA).

Gradient polymerase chain reaction (PCR) was performed at a 45 to $60^{\circ} \mathrm{C}$ annealing temperature using 20 pairs of SSR primers and one isolate; $50^{\circ} \mathrm{C}$ yielded the best result and was used in subsequent studies. Each PCR was conducted in a 10- $\mu 1$ mixture containing $5 \times$ Clear GoTaq reaction buffer ( $2 \mu \mathrm{l}$; Promega Corp., Madison, WI), $2.5 \mathrm{mM}$ dNTP $(0.8 \mu \mathrm{l}), 25 \mathrm{mM} \mathrm{MgCl} 2(1 \mu \mathrm{l})$, GoTaq DNA polymerase (0.04 $\mu \mathrm{l}$; Promega Corp.), M13-tagged forward primer $(0.5 \mu \mathrm{l})$ and reverse primer $(2.0 \mu \mathrm{l})$ (both at $1 \mu \mathrm{M}), 1 \mu \mathrm{M}$ M13 primer (M13-TGTAAAACGACGGCCAGT) fluorescently labeled with the IRDye $800 \mathrm{CW}$ fluorophore $(1.8 \mu \mathrm{l}$; Eurofins MWG Operon, Huntsville, AL), sterile water $(0.86 \mu \mathrm{l})$, and $1 \mu \mathrm{l}$ of $P$. nicotianae isolate DNA $(2.5 \mathrm{ng} / \mu \mathrm{l})$. PCR was conducted as an initial denaturation $\left(94^{\circ} \mathrm{C}, 3 \mathrm{~min}\right), 9^{\circ} \mathrm{C}$ for $30 \mathrm{~s}$ for 39 cycles, $50^{\circ} \mathrm{C}$ for $60 \mathrm{~s}, 72^{\circ} \mathrm{C}$ for $70 \mathrm{~s}$, and a final extension for $10 \mathrm{~min}$ at $72^{\circ} \mathrm{C}$. The product of PCR $(2 \mu \mathrm{l})$ was mixed with $5 \mu$ l of Blue Stop solution (LI-COR Biosciences, Lincoln, NE), and $0.3 \mu \mathrm{l}$ of the mixture was used to run a polyacrylamide gel (6.5\%) using a 4300 DNA Analyzer (LI-COR). Seven pairs of primers were selected (Table 2) because these loci generated polymorphisms among the 59 isolates and these markers were used for SSR analysis using the conditions described above. The presence or absence of a band (coded as 1 or 0 , respectively) on the gel images for different sizes of the alleles was recorded for unweighted pair group method with arithmetic means (UPGMA) and the Structure analyses.

Marker data were loaded into NTSTSpc (Rohlf 2008) for the UPGMA cluster analysis. The SIMQUAL module in NTSYSpc software was used to calculate genetic similarity between each pair of $P$. nicotianae isolates based on DICE coefficient of similarity (Nei and Li 1979). The SAHN module of NTSYSpc (UPGMA procedure) was used to generate a dendrogram based on matrix of similarity. FreeTree program (Hampl et al. 2001) was used to conduct bootstrapping analysis, which estimates the reliability of individual branching points of a tree, and the number of repetitions was 1,000. Values of bootstrap larger than $50 \%$ were shown, except that the bootstrap value for the major groups was shown.

Structure version 2.3.4 (Pritchard et al. 2000) was used for a Bayesian analysis using the admixture model, which infers whether the individual $i$ has inherited a portion of its genetic material from ancestors in population $k$. For measuring different $k$ values, 20 independent replicates were made for each $k$ value between 1 and 10 for the sampling locations and race data. A burn-in period of 250,000 iterations and 250,000 Markov Chain Monte Carlo repetitions were used in all analyses. Estimation of the best $k$ value was determined by Structure Harvester (Earl and von Holdt 2012), which determines appropriately how many clusters $(k)$ there are using the ad hoc statistic $\Delta k$. This is according to the second-order rate of change in the log probability of the data between successive values of $k$. The analysis was performed twice: once with isolates grouped by location and once with isolates grouped by race. The Excel add-in GenAlEx 6.5 (Peakall and Smouse 2012) was used to calculate pairwise population differentiation (fixation index $\left[F_{S T}\right]$ ) for location and race.

\section{Results}

Race and mating type determination. About half of the isolates (30 of 59) were identified as race 0 that caused disease on K326 but not L8 and NC1071. Twenty-three isolates were race 1 that caused disease on K326, L8, and NC1071. Six isolates caused disease on K326 and L8 but did not cause disease on NC1071, and hence were identified as race 3 (Table 1). Most isolates were identified as the A2 mating type and three isolates (Pn21A, Pn38A, and Pn207A) were A1.

Sensitivity of $\boldsymbol{P}$. nicotianae isolates to mefenoxam. Among the isolates, 55.9 and $44.1 \%$ were sensitive or intermediately sensitive, respectively, to mefenoxam at $1 \mu \mathrm{g} / \mathrm{ml}$ (Table 1). For mefenoxam at $10 \mu \mathrm{g} / \mathrm{ml}, 94.9$ and $5.1 \%$ of the isolates were sensitive or intermediately sensitive, respectively. Isolates Y201, Pn13B, and Pn29A had relatively higher $\mathrm{EC}_{50}$ values than other isolates but isolates resistant to the compound were not found. $\mathrm{EC}_{50}$ values of mefenoxam for inhibition of mycelium growth of the isolates were $<0.01$ to $0.12 \mu \mathrm{g} / \mathrm{ml}$ (Fig. 1).

Genetic diversity of $\boldsymbol{P}$. nicotianae isolates. Among the 20 SSR primer pairs tested, 7 pairs of primers produced nine reproducible polymorphic bands (alleles). DICE genetic similarity coefficients between the 59 isolates ranged from 0.22 to 1.0 , with a mean of 0.71 . Using UPGMA cluster analysis, the isolates can be placed in two

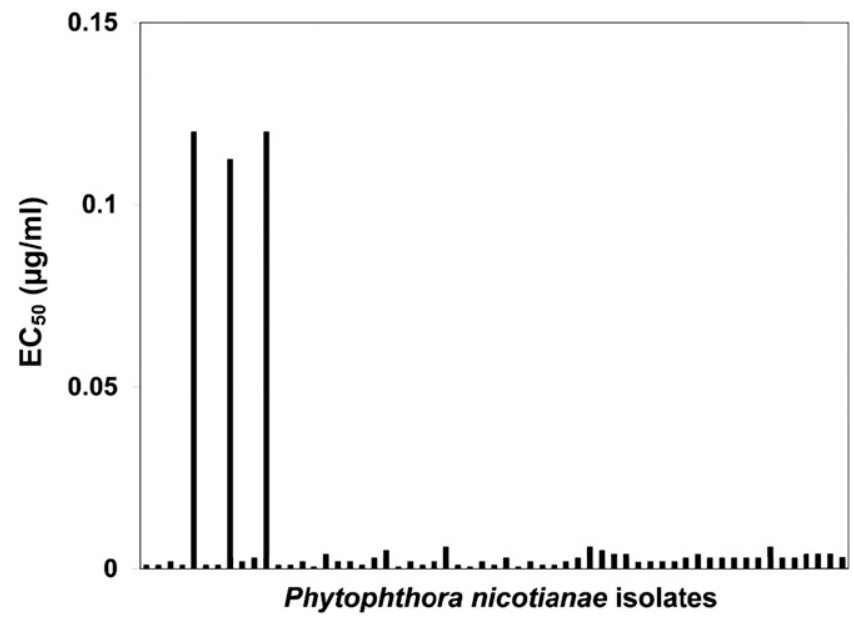

Fig. 1. Concentration of mefenoxam for suppressing $50 \%$ of mycelial growth $\left(\mathrm{EC}_{50}\right)$ of Phytophthora nicotianae isolates.

Table 2. Primer sequences of simple sequence repeats markers used to study genetic diversity of Phytophthora nicotianae isolates

\begin{tabular}{|c|c|c|c|c|}
\hline Locus & Primer sequence $5^{\prime}$ - $3^{\prime}$ & Repeat motif & Scored alleles $(n)$ & Allele size $(\mathbf{b p})^{\mathrm{a}}$ \\
\hline \multirow[t]{2}{*}{ Pn176 } & F: TGTCCTTCGCTCACTATTTACG & $(\mathrm{TC})_{33}$ & 2 & 145,147 \\
\hline & R: CTGTTGGTGTTACGGGGTATTT & $\ldots$ & $\ldots$ & \\
\hline \multirow[t]{2}{*}{ Pn189 } & F: AGCGAGAATACCTTTGTGTGGT & $(\mathrm{CT})_{17}$ & 1 & 200 \\
\hline & R: CGGTTGAATCGAGATATCCTACA & $\ldots$ & $\ldots$ & $\ldots$ \\
\hline \multirow[t]{2}{*}{$\operatorname{Pn} 251$} & F: CCTGACACTTACCACCAACTCA & $(\mathrm{CTCA})_{10}$ & 2 & 165,172 \\
\hline & R: TAAATTTGCAGCGTTCCATAAG & $\ldots$ & $\ldots$ & \\
\hline \multirow[t]{2}{*}{ Pn372 } & F: TTATGCTGACGTAGCGCTGTAT & $(\mathrm{AT})_{14}$ & 1 & 156 \\
\hline & R: ATCTAATGCCTTTGTCGTTCGT & & $\ldots$ & \\
\hline \multirow[t]{2}{*}{$\operatorname{Pn} 410$} & F: CCTTCATCTTGTACGGGACATT & $(\mathrm{TC})_{15}$ & 1 & 151 \\
\hline & R: ACGAAAATCAACGGTTCCAATA & $\ldots$ & $\ldots$ & $\ldots$ \\
\hline \multirow[t]{2}{*}{ Pn511 } & F: GGAGAAGTGCTCTTCGTTGTCT & $(\mathrm{ACG})_{8}$ & 1 & 180 \\
\hline & R: CAACGGGAGCATCGGTAG & $\ldots$ & $\ldots$ & $\ldots$ \\
\hline \multirow[t]{2}{*}{ Pn535 } & F: GCCAACTCCATCATCATCATC & $(\mathrm{TTC})_{8}$ & 1 & 180 \\
\hline & R: TTAACAATGGAGACCCGAACTT & $\ldots$ & $\ldots$ & \\
\hline
\end{tabular}

${ }^{a}$ Markers with only one scored allele were dominant loci (presence or absence). 
groups (Fig. 2). There were 20 isolates in group I; all were isolated from Berrien County, except for one isolate, Pn112A, from Cook County. Additionally, 15 of 20 isolates in group I were identified as race 1, whereas the other isolates were either race 0 (Pn105A, Pn12A, and Pn18B) or race 3 (Pn18A and Pn104A). There were 39 isolates in group II that were isolated from Bacon, Cook, Tift, and Toombs Counties, except one isolate, Pn13B, from Berrien County. The majority of the race 0 isolates were in group II ( 27 of 30 ).

Structure analyses found evidence of two distinct clusters and supported the UPGMA cluster analysis (Fig. 3). In agreement with the UPGMA cluster analysis, Structure analysis, represented as bar plots of individual Bayesian assignment probabilities of $P$. nicotianae isolates, displayed the finding that isolates placed in group I (shaded in red) were primarily from Berrien County, GA, whereas isolates collected from Bacon, Cook, Tift, and Toombs Counties were primarily in group II (green shading). Finally, Structure analysis was in agreement with UPGMA clustering, because the Bayesian assignment probabilities for $P$. nicotianae isolates also showed that most isolates that were race 0 belonged to group II whereas most of the isolates that were race 1 belonged to group I.

The $F_{S T}$ is used to estimate the degree of population differentiation. It is suggested that $F_{S T}$ values of 0 to 0.05 represent little genetic differentiation, 0.05 to 0.15 represent moderate genetic differentiation, 0.15 to 0.25 represent great genetic differentiation, and $F_{S T}$ values greater than 0.25 represent very great genetic differentiation (Hartl and Clark 1997). Pairwise comparisons of population differentiation $\left(F_{S T}\right)$ for sampling location and race of $P$. nicotianae support
UPGMA and Structure analyses (Tables 3 and 4), because Berrien County, GA, is highly differentiated from the other counties $\left(F_{S T} \geq 0.64\right)$ and races 0 and 1 are also highly differentiated.

\section{Discussion}

Tobacco is an economically important crop in Georgia, with over 6,500 ha produced and a farm gate value of approximately $\$ 80$ million annually (Wolfe and Stubbs 2015). Black shank has been one of the most devastating diseases affecting tobacco production in the southeastern United States (Csinos 2005; Csinos and Bertrand 1994; Shew and Lucas 1998). Studies conducted over a decade ago indicated that two races of $P$. nicotianae (races 0 and 1) were present in commercial tobacco fields in Georgia (Csinos 2005). However, genetic diversity of $P$. nicotianae populations and the prevalent races currently affecting tobacco production in Georgia are unknown. In the present study, we identified two genetic groups of $P$. nicotianae isolates from tobacco in Georgia using SSR markers. Races 0 and 1 were the prevailing races known to occur in Georgia prior to our study (Csinos 2005). We, for the first time, identified race 3 in Georgia, providing information on the population structure of $P$. nicotianae that can be used for designing effective management programs for black shank.

Both races 0 and 1 were found in different areas in Georgia in the study, which is in agreement with findings from earlier studies. It was reported that races 1 and 0 of $P$. nicotianae were widely distributed in tobacco-producing regions in Georgia, with an increase of race 1 population from $16 \%$ (Csinos and Bertrand 1994) to $83 \%$ (Csinos

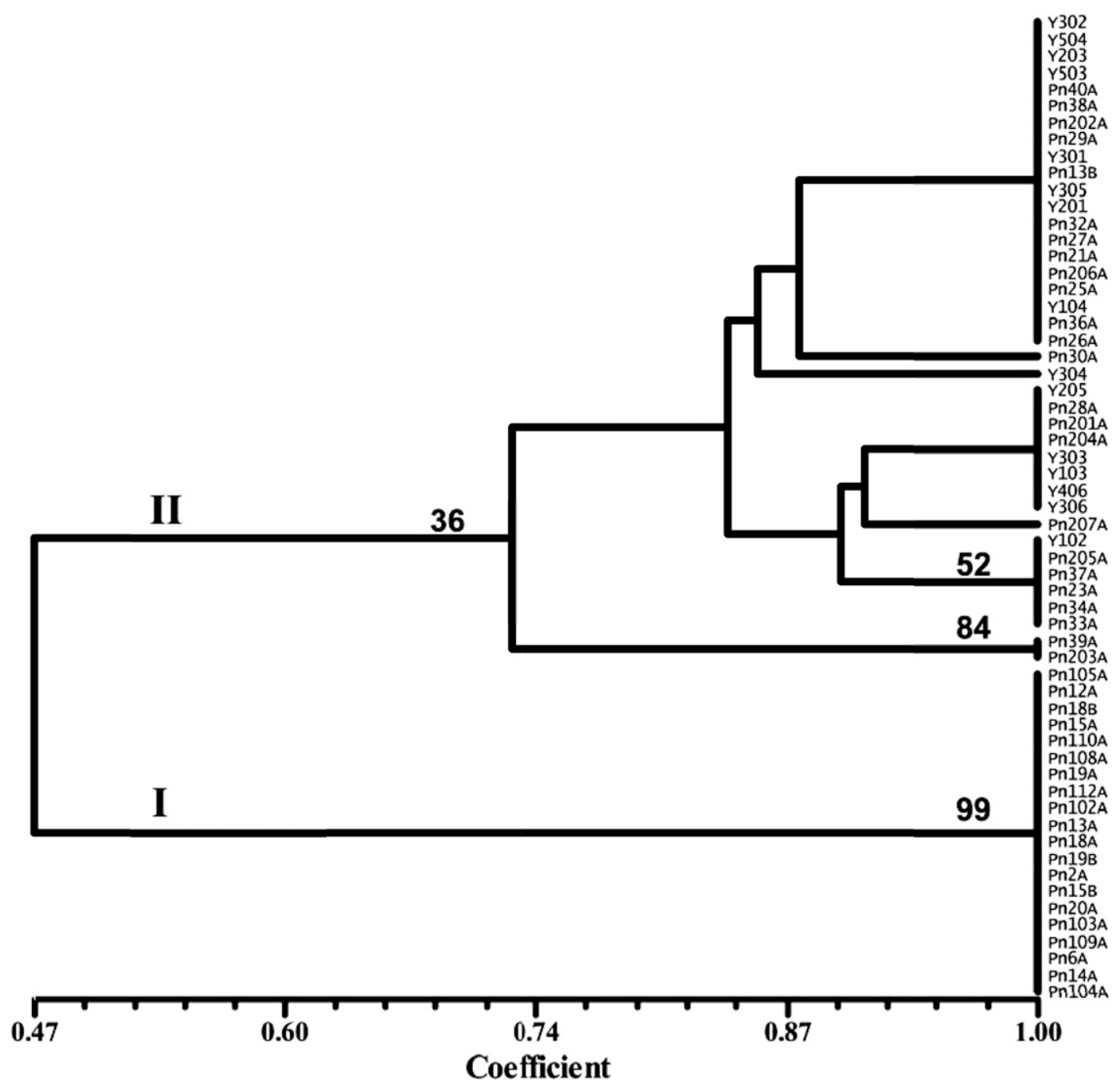

Fig. 2. Unweighted pair group method with arithmetic mean cluster analysis of Phytophthora nicotianae isolates. 
2005), probably due to increased use of $P h$ gene-carrying tobacco cultivars. In the present study, 50.8 and $39.0 \%$ of the isolates were identified as race 0 or 1 , respectively, indicating that the two races are currently the dominant races. About $10 \%$ of the isolates we collected in Georgia were race 3 and not reported previously in the state. Race 3 of $P$. nicotianae was first identified in Connecticut in the 1970s (McIntyre and Taylor 1978). More recently, it was reported in North Carolina (Gallup and Shew 2010) and Virginia (Parkunan et al. 2010). Existence of race 3 in Georgia indicates that this race is widely distributed in the southeastern United States.

Mefenoxam or metalaxyl (active ingredient: mefenoxam) is the primary fungicide used to control black shank in tobacco. An earlier study conducted in Georgia showed that tobacco $P$. nicotianae isolates had different sensitivity to metalaxyl, with $\mathrm{ED}_{50}$ ranging from 0.96 to $<0.01 \mu \mathrm{g} / \mathrm{ml}$ (Csinos and Bertrand 1994). It appeared that sensitivity of $P$. nicotianae isolates in Georgia to mefenoxam did not reduce over the last two decades because the $\mathrm{EC}_{50}$ for inhibiting mycelial growth of the isolates, in the present study, ranged from $<0.01$ to $0.12 \mu \mathrm{g} / \mathrm{ml}$. Resistance to mefenoxam has not been reported in isolates of $P$. nicotianae from tobacco. In South Africa, sensitivity of 132 P. nicotianae isolates from tobacco to metalaxyl was studied (Van Jaarsveld et al. 2002). Metalaxyl at $1.0 \mu \mathrm{g} / \mathrm{ml}$ completely inhibited growth of most of the isolates, although isolates from some areas had higher $\mathrm{EC}_{50}$ values of 1.02 to $3.57 \mu \mathrm{g} / \mathrm{ml}$. Studies with isolates of $P$. nicotianae from tobacco in North Carolina for sensitivity to metalaxyl indicated that $\mathrm{ED}_{50}$ values were 0.3 to $1.2 \mu \mathrm{g} / \mathrm{ml}$ (Shew 1985). A more recent study showed that the majority of $P$. nicotianae isolates from tobacco in Virginia were highly sensitive to mefenoxam and a few isolates were intermediately sensitive, suggesting that mefenoxam remained effective for black shank management (Parkunan et al. 2010).

Genetic diversity of $P$. nicotianae isolates from tobacco has been assessed in a few studies. Genetic variation of isolates of $P$. nicotianae in a single tobacco field in North Carolina was determined by amplified fragment length polymorphism (AFLP) analysis (Sullivan et al. 2010). About half of the isolates were clustered in one genetic group and the other half were divided into 27 AFLP groups, with no relationship between races ( 0 and 1 ) and AFLP groups. Diversity of 63 isolates from tobacco in China was assessed using randomly amplified polymorphic DNA (RAPD) analysis (Zhang et al. 2003). The isolates were clustered in two major groups, with no relationship between RAPD groups and geographical origins of the isolates. In a recent study (Biasi et al. 2016), diversity of 20 isolates of $P$. nicotianae from tobacco was evaluated by SSR markers. Variability among the isolates was observed and genetic variation was associated with geographical locations of isolation. In the present study, the P. nicotianae isolates from different locations in Georgia were grouped in two major clusters by SSR analysis. The groupings were based on

Table 4. Pairwise fixation index values for races of Phytophthora nicotianae isolates $^{\mathrm{a}}$

\begin{tabular}{lccc}
\hline Race & Race 0 & Race 1 & Race 3 \\
\hline Race 0 & $\ldots$ & $\ldots$ & $\ldots$ \\
Race 1 & $0.29^{*}$ & $\ldots$ & $\ldots$ \\
Race 3 & 0.00 & 0.07 & $\ldots$ \\
\hline
\end{tabular}

a Asterisk (*) indicates significant at $P<0.001$ based on 9,999 permutations.

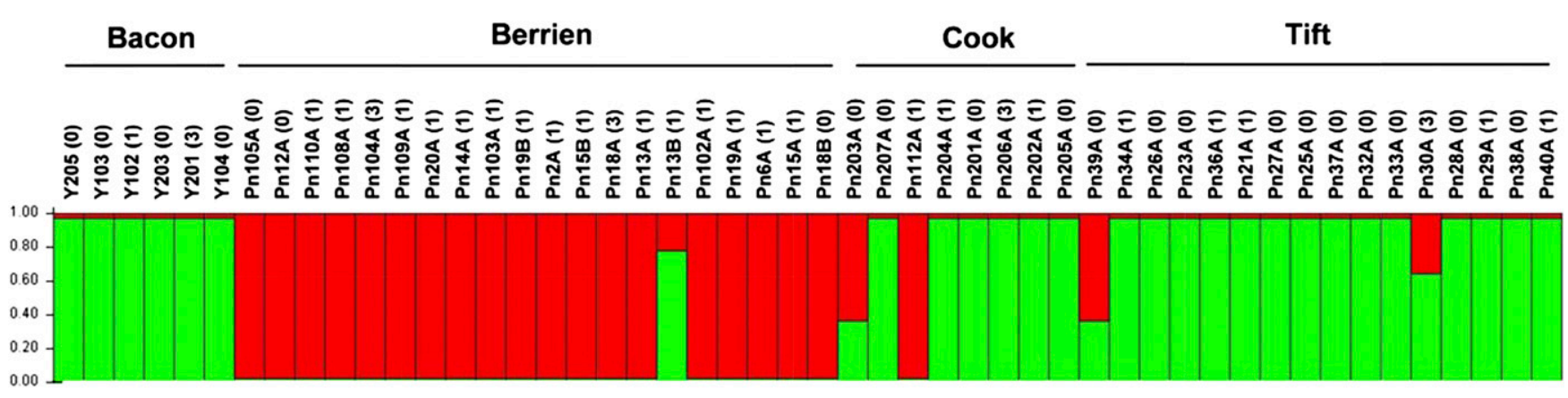

Toombs

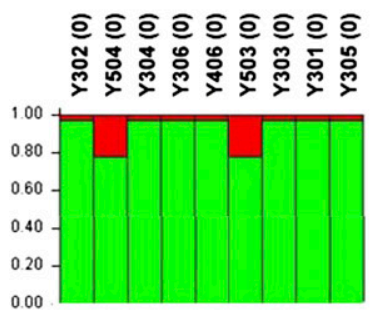

Fig. 3. Bar plots of individual Bayesian assignment probabilities of simple sequence repeats for Phytophthora nicotianae isolates using the program Structure for two clusters. Each vertical line represents an individual's probability of belonging to one of $k$ clusters (represented by different colors) or a combination if ancestry is mixed. For each isolate, race designation is provided in parentheses.

Table 3. Pairwise fixation index values based on collection location of Phytophthora nicotianae isolates in Georgia ${ }^{\mathrm{a}}$

\begin{tabular}{|c|c|c|c|c|c|}
\hline Location & Bacon County & Berrien County & Cook County & Tift County & Toombs County \\
\hline Bacon County & & $\ldots$ & $\ldots$ & $\ldots$ & $\ldots$ \\
\hline Berrien County & $0.78^{*}$ & $\ldots$ & $\ldots$ & $\ldots$ & $\ldots$ \\
\hline Cook County & 0.00 & $0.64 *$ & $\ldots$ & $\ldots$ & $\ldots$ \\
\hline Tift County & 0.00 & $0.76^{*}$ & $0.07 * *$ & $\ldots$ & $\ldots$ \\
\hline Toombs County & 0.00 & $0.77 *$ & $0.11^{* *}$ & 0.03 & $\ldots$ \\
\hline
\end{tabular}

${ }^{a}$ Asterisks $*$ and $* *$ indicate significant at $P<0.001$ and 0.05 , respectively, based on 9,999 permutations. 
collection location, and group I was primarily composed of isolates that were race $1(75 \%)$ and group II isolates were primarily $(69 \%)$ race 0 . These findings are in agreement with the previous studies that $P$. nicotianae populations on tobacco are genetically diverse.

The majority of isolates sampled from Georgia were the A2 mating type. The existence of a single mating type of the pathogen in most of the sampling fields may imply low probability of sexual recombination, which could have contributed to the low genetic diversity at a particular geographical location. It was reported (Parkunan et al. 2010 ) that the majority (about $94 \%$ ) of P. nicotianae isolates from tobacco in Virginia were the A2 mating type and $6 \%$ of the isolates were A1. In another study (Peng et al. 2011), P. nicotianae isolated from tobacco in Guizhou, China, were determined to be A2 and other mating types were not present, indicating a low possibility of sexual recombination.

In summary, this study provides new insights into the current status and diversity of $P$. nicotianae affecting tobacco in Georgia. A new race (race 3 ) was identified in the state for the first time, and all isolates were found to be sensitive or intermediately sensitive to mefenoxam, which is valuable information for tobacco growers to manage the disease. The SSR markers used in this study were a useful tool to analyze genetic diversity of the pathogen, which revealed that $P$. nicotianae populations isolated from tobacco grown in Georgia could be classified into two groups. Further research to monitor potential gene migration among populations of the pathogen at different locations would advance our understanding of the spread and ecology of this important pathogen in tobacco production.

\section{Literature Cited}

Apple, J. L. 1967. Occurrence of race 1 of Phytophthora parasitica var. nicotianae in North Carolina and its implications in breeding for disease resistance. Tob. Sci. 11:79-83.

Biasi, A., Martin, F. N., Cacciola, S. O., di San Lio, G. M., Grünwald, N. J., and Schena, L. 2016. Genetic analysis of Phytophthora nicotianae populations from different hosts using microsatellite markers. Phytopathology 106:1006-1014.

Csinos, A. S. 2005. Relationship of isolate origin to pathogenicity of race 0 and 1 of Phytophthora parasitica var. nicotianae on tobacco cultivars. Plant Dis. 89: 332-337.

Csinos, A. S., and Bertrand, P. F. 1994. Distribution of Phytophthora parasitica var. nicotianae races and their sensitivity to metalaxyl in Georgia. Plant Dis. 78:471-474.

Earl, D. A., and von Holdt, B. M. 2012. Structure Harvester: A website and program for visualizing Structure output and implementing the Evanno method. Conserv. Genet. Resour. 4:359-361.

Erwin, D. C., and Ribeiro, O. K. 1996. Phytophthora nicotianae. Pages 391-407 in: Phytophthora Diseases Worldwide. American Phytopathological Society, St. Paul, MN.

Gallup, C. A., and Shew, H. D. 2010. Occurrence of race 3 of Phytophthora nicotianae in North Carolina, the causal agent of black shank of tobacco. Plant Dis. 94:557-562.
Hampl, V., Pavlícek, A., and Flegr, J. 2001. Construction and bootstrap analysis of DNA fingerprinting-based phylogenetic trees with a freeware program FreeTree: Application to trichomonad parasites. Int. J. Syst. Evol. Microbiol. 51:731-735.

Hartl, D. L., and Clark, A. G. 1997. Principles of Population Genetics, 3rd ed Sinauer Associates, Inc., Sunderland, MA.

Ji, P., Csinos, A. S., Hickman, L. L., and Hargett, U. 2014. Efficacy and application methods of oxathiapiprolin for management of black shank on tobacco. Plant Dis. 98:1551-1554.

Lamprecht, M. P., Prinsloo, G. C., and van Wyk, R. J. 1974. Inheritance of resistance to race 2 of the black shank fungus, Phytophthora nicotianae (B. de Haan) var. nicotianae, of tobacco. Agroplantae 6:73-76.

McIntyre, J. L., and Taylor, G. S. 1978. Race 3 of Phytophthora parasitica var nicotianae. Phytopathology 68:35-38.

Nei, M., and Li, W. H. 1979. Mathematical model for studying genetic variation in terms of restriction endonucleases. Proc. Natl. Acad. Sci. USA 76:5269-5273.

Parkunan, V., Johnson, C. S., Bowman, B. C., and Hong, C. X. 2010. Population structure, mating type, and mefenoxam sensitivity of Phytophthora nicotianae in Virginia tobacco fields. Plant Dis. 94:1361-1365.

Peakall, R., and Smouse, P. E. 2012. GenAlEx 6.5: Genetic analysis in Excel. Population genetic software for teaching and research-an update. Bioinformatics 28:2537-2539.

Peng, L. J., Ding, H. X., and Ge, Y. Y. 2011. Mating type and distribution of Phytophthora nicotianae in Guizhou province. J. Henan Agric. Sci. 40:93-96.

Pritchard, J. K., Stephans, M., and Donnelly, P. 2000. Inference of population structure using multilocus genotype data. Genetics 155:945-959.

Qu, T., Shao, Y., Csinos, A. S., and Ji, P. 2016. Sensitivity of Phytophthora nicotianae from tobacco to fluopicolide, mandipropamid and oxathiapiprolin. Plant Dis. 100:2119-2125.

Rohlf, F. J. 2008. NTSYSpc: Numerical Taxonomy System, Version 2.20. Exeter Publ., Setauket, NY.

Shew, H. D. 1985. Response of Phytophthora parasitica var. nicotianae to metalaxyl exposure. Plant Dis. 69:559-562.

Shew, H. D., and Lucas, G. B. 1998. Compendium of Tobacco Diseases, 2nd ed American Phytopathological Society, St. Paul, MN.

Sullivan, M. J., Parks, E. J., Cubeta, M. A., Gallup, C. A., Melton, T. A., Moyer, J. W., and Shew, H. D. 2010. An assessment of the genetic diversity in a field population of Phytophthora nicotianae with a changing race structure. Plant Dis. 94:455-460.

Van Jaarsveld, E., Wingfield, M. J., and Drenth, A. 2002. Evaluation of tobacco cultivars for resistance to races of Phytophthora nicotianae in South Africa. J. Phytopathol. 150:456-462.

Wang, Z., Langston, D. B., Csinos, A. S., Gitaitis, R. D., Walcott, R. R., and Ji, P. 2009. Development of an improved isolation approach and simple sequence repeat markers to characterize Phytophthora capsici in irrigation ponds in southern Georgia. Appl. Environ. Microbiol. 75:5467-5473.

Wolfe, K., and Stubbs, K. 2015. 2014 Georgia Farm Gate Value Report. AR-1501. The Center for Agribusiness and Economic Development, University of Georgia College of Agricultural and Environmental Sciences, Athens, GA.

You, F. M., Huo, N., Gu, Y. Q., Luo, M., Ma, Y., Hane, D., Lazo, G. R., Dvorak, J., and Anderson, O. D. 2008. BatchPrimer3: A high throughput web application for PCR and sequencing primer design. BMC Bioinformatics 9:253.

Zhang, X. G., Sun, W. X., Guo, L., Yu, J. F., and Chang, C. J. 2003. Genetic and pathogenic variation among tobacco black shank strains of Phytophthora parasitica var. nicotianae from the main tobacco growing in China. J. Phytopathol. 151:259-266. 